\title{
ACCOUNTABILITY: A RAZÃO DE SER DA CONTABILIDADE
}

\section{THE REASON FOR THE EXISTENCE OF ACCOUNTANCY}

\section{ACCOUNTABILITY: LA RAZÓN DE SER DE LA CONTABILIDAD}

\begin{abstract}
MASAYUKI NAKAGAWA, MIBA
Professor Titular em Contabilidade e Controladoria da FEAUSP, Membro do Instituto Brasileiro de Atuária, Chair Professor Ford de Logística Integrada à Controladoria e Negócios, Autor de Livros. nakawa@usp.br

\section{TÂNIA REGINA SORDI RELVAS}

Professora Assistente Doutora em Contabilidade e Controladoria da FEA/USP. Membro do Laboratório de Pesquisa em Logística Integrada à Controladoria e Negócios (Logicon) da FIPECAFI. Possui larga experiência em consultoria na implantação dos métodos de custeio e gestão baseadas em atividades: $A B C / A B M$.

taniarsr@uol.com.br
\end{abstract}

\section{JOSÉ MARIA DIAS FILHO}

Professor Titular de Contabilidade da Universidade Federal da Bahia. Em seu mestrado e doutorado em Controladoria e Contabilidade pela FEA/USP foi o pioneiro na aplicação de conceitos de Semiótica Aplicada à Contabilidade obtendo a classificação de melhor Tese de Doutorado do Departamento de Contabilidade Atuaria da FEA/USP em 2004.

zemariadias@uol.com.br

"I am sure that all of us who teach accounting in universities suffer from the implied contempt of our colleagues, who look upon accounting as an intruder, a Saul among the prophets, a pariah whose very presence detracts somewhat from the sanctity of the academic halls". 


\section{RESUMO}

Este trabalho teve como objetivo compreender se a accountability é, ou não, a razão de ser da Contabilidade. Se a resposta for positiva e corretamente compreendida pelos professores, pesquisadores e profissionais da Contabilidade, poderemos alimentar a esperança de que o nosso status social, político e econômica atingirá brevemente o nível desejado por todos nós, na mesma medida em que o conceito de accountability for aplicado em nosso País, com due diligence. As pesquisas que vêm sendo realizadas há mais de 15 (quinze) anos na Fundação Instituto de Pesquisas Contábeis, Atuariais e Financeiras (Fipecafi) vinculada à FEA/USP, revelam que, no mundo dos negócios públicos e privados, existem basicamente duas formas de accountability, uma delas é de natureza exógena e outra endógena. As duas formas de accountability contribuem para a compreensão do conceito de plena accountability a que se refere o modelo de governança empresarial da International Federation of Accountants (Ifac). A pesquisa de campo que, no início dos anos 90 , foi objeto de uma consulta da diretoria para a América do Sul e Caribe do Banco Mundial à Fipecafi, com o objetivo de se mensurar o nível de accountability no Brasil, tanto no setor público como privado, é algo que ainda permanece em aberto, como desafio para os futuros pesquisadores desse tema.

Palavras-Chaves: Governança Empresarial, Ciências Contábeis, Contabilização, Contabilidade, Prestação de Contas e Accountability.

\section{ABSTRACT}

Accountability as the true meaning of accounting was the main purpose of this work of research. Being the answer for this question positive or correctly understood by all professors, researchers and accounting professionals, we could fortunately hope that our desired social, political and economical status will be reached soonest possible accordingly to the application of accountability concept in a due diligence way. The researches on accountability at Fipecafi and FEA/USP for more than 15 years disclose us that in the private and governmental business environment there are basically two forms of accountability, one is of exogenous nature and the other endogenous. Both forms of accountability contribute to the understanding of the plain accountability concept in the Ifac's enterprise governance model. The field research that in the 90 s early years was on demand for the General Manager of the World Bank at South America and Caribe continue to be open and remain as something challenging for future researchers on this issue.

Keywords: Enterprise Governance, Accountancy, Bookkeeping, Accounting, Settle Accounts and Accountability. 


\section{RESUMEN}

Este trabajo tuvo como objetivo comprender si la accountability es, o no, la razón de ser de la Contabilidad. Si la respuesta es positiva y correctamente comprendida por los maestros, investigadores y profesionales de la Contabilidad, podremos alimentar la esperanza de que nuestro estatus social, político y económica alcanzará brevemente el nivel deseado por todos nosotros, en la misma medida en la que el concepto de accountability sea aplicado en nuestro País, con due diligence. Las pesquisas que vienen siendo realizadas hace más de 15 (quince) años en la Fundación Instituto de Investigaciones Contables, Actuarias y Financieras (Fipecafi) vinculada a la FEA/USP, revelan que, en el mundo de los negocios públicos y privados, existen básicamente dos formas de accountability, de ellas es de naturaleza exógena y otra endógena. Las dos formas de accountability aportan para la comprensión del concepto de plena accountability a que se refiere el modelo de gobierno empresarial de la International Federation of Accountants (Ifac). La pesquisa de campo que, en el inicio de los años 90, fue objeto de una consulta de la directoria para América del Sur y Caribe del Banco Mundial a la Fipecafi, con el objetivo de medirse el nivel de accountability en Brasil, tanto en el sector público como privado, es algo que aún permanece en abierto, como desafío para los porvenires encuestadores de esa tema.

Palabras-Claves: Gobierno Empresarial, Ciencias Contables, Contabilización, Contabilidad, Prestación de Cuentas y Accountability.

\section{CONTEXTUALIZAÇÃO}

Para todos nós que nos dedicamos com due diligence ao ensino, à pesquisa e ao exercício profissional em Contabilidade, apreciaríamos muito que o nosso status social, político e econômico fosse considerado, pelo menos, de igual nível ao dos colegas de outras áreas tradicionais do conhecimento humano. Mas não é isso que acontece. Aliás, já em 1923, o professor Henry Rand Hatfield já se manifestava, em um congresso de Contabilidade, extremamente preocupado como os colegas de outras áreas do conhecimento humano desconheciam o verdadeiro significado social, político e econômico da nossa profissão.

Por outro lado, em 1965, o professor Vernon Kam formulou, no Capítulo 2 do seu livro Teoria da Contabilidade, a seguinte pergunta provocativa: o que é contabilidade? Segundo ele, essa questão tão óbvia quanto básica para a formação do contador e melhoria da prática contábil nundial não foi respondida até hoje de maneira adequada.

Em 1975, o professor Yuji ljiri, do Curso de Administração Industrial da Carnegie Mellon University, manifestou, com muita clareza, em seu livro Teoria da Mensuração Con- 
tábil, a opinião de que sob o ponto de vista social e organizacional, a accountability tem sido considerada por muitos séculos como sendo a razão de ser da contabilidade. Em 1992, os professores Hendriksen e Van Breda afirmaram com muita convicção, no seu livro sobre Teoria da Contabilidade, que a accountability é o início e fim da contabilidade.

Em 1995, o professor Sergio de ludícibus afirmou em seu livro Teoria da Contabilidade que, para se compreender o que a contabilidade é em sua essência, será necessário observar atentamente o que a contabilidade realiza dentro da atividade econômica.

Em 2004, o International Federation of Accountants (Ifac) editou o trabalho intitulado Enterprise Governance-Getting the Balance Right, defendendo o conceito de plena accountability, com foco na conformidade contábil das empresas às leis que regulam suas atividades e no desempenho econômico-financeiro do seu negócio.

Em 2005, por meio do Ofício-Circular/CVM/SNC/SEP № 01/2005, a Comissão de Valores Mobiliários (CVM) emitiu ao mercado financeiro orientação sobre a elaboração de Informações Contábeis pelas Companhias Abertas e, por meio da Deliberação CVM Nº 488/2005, aprovou o Pronunciamento do Instituto Brasileiro de Contadores (Ibracon) NPC № 27 sobre elaboração e divulgação de Demonstrações Contábeis.

Em 2005, o Conselho Federal de Contabilidade (CFC), a pedido da Associação dos Analistas e Profissionais de Investimentos do Mercado de Capitais (Apimec), Associação Brasileira das Companhias Abertas (Abrasca), Fundação Instituto de Pesquisas Contábeis, Atuariais e Financeiras conveniada à FEA/USP (Fipecapi) e Instituto dos Auditores Independentes do Brasil (Ibracon), emitiu a Resolução N¹055 criando o Comitê de Pronunciamentos Contábeis (CPC), com a missão de deliberar em matéria de pronunciamentos técnicos, interpretações e orientações, no contexto do movimento mundial de convergência entre os padrões contábeis internacionais do Financial Accounting Standards Board (Fasb) e do International Accounting Standards Board (lasb).

Em 9 de maço de 2007, a Diretoria Colegiada do Banco Central do Brasil (BCB) determinou a obrigatoriedade da elaboração e da divulgação de demonstrações financeiras consolidadas dos bancos brasileiros, de conformidade com os padrões contábeis internacionais do International Financial Reporting Standards (IFRS) a partir de 2010.

Em 13 de julho de 2007, a Comissão de Valores Mobiliários (CVM) por meio da Instrução CVM N457, determinou a obrigatoriedade da elaboração e da divulgação das demonstrações financeiras consolidadas das sociedades anônimas de capital aberto, de acordo com os padrões contábeis internacionais do International Financial Reporting Standards (IFRS) a partir de 2010.

Quais serão as implicações estratégicas dos pronunciamentos e das normas legais acima referidas sobre o desempenho econômico-financeiro dos negócios das empresas brasileiras e sua conformidade às leis e aos padrões contábeis internacionais do IFRS, em termos de plena accountability a que se refere a Ifac? Essa é a questão-chave a ser respondida neste trabalho. 
O presente trabalho é uma relevante contribuição ao meritório trabalho de colaboração do Conselho Federal de Contabilidade (CFC) perante as Instituições de Ensino Superior (IESs), que mantêm cursos de graduação em Ciências Contábeis, na busca de um novo modelo de educação contábil no Brasil.

Assumimos como pressuposto básico para as pesquisas a serem realizadas neste trabalho que somente a integração conceitual e sistêmica entre as atividades de contabilização (bookeeping) e contabilidade (accounting) contribuirá para a otimização das abordagens sintática, semântica e pragmática aplicadas ao ensino e à pesquisa nos cursos de graduação em Ciências Contábeis (accountancy), com foco na compreensão do conceito de que a accountability é a razão de ser da Contabilidade.

\section{PESQUISA BIBLIOGRÁFICA}

a. O Modelo de Governança Empresarial da Ifac e o Curso de Graduação em Ciências Contábeis (Accountancy) no Brasil.

\subsubsection{O Modelo de Governança Empresarial com Plena Accountability da Ifac}

A International Federation of Accountants (Ifac) publicou em 2004 o trabalho intitulado Enterprise Governance-Getting the Balance Right, dando ênfase ao conceito de plena accountability, no contexto do seu modelo de governança empresarial, representado por meio da seguinte figura:

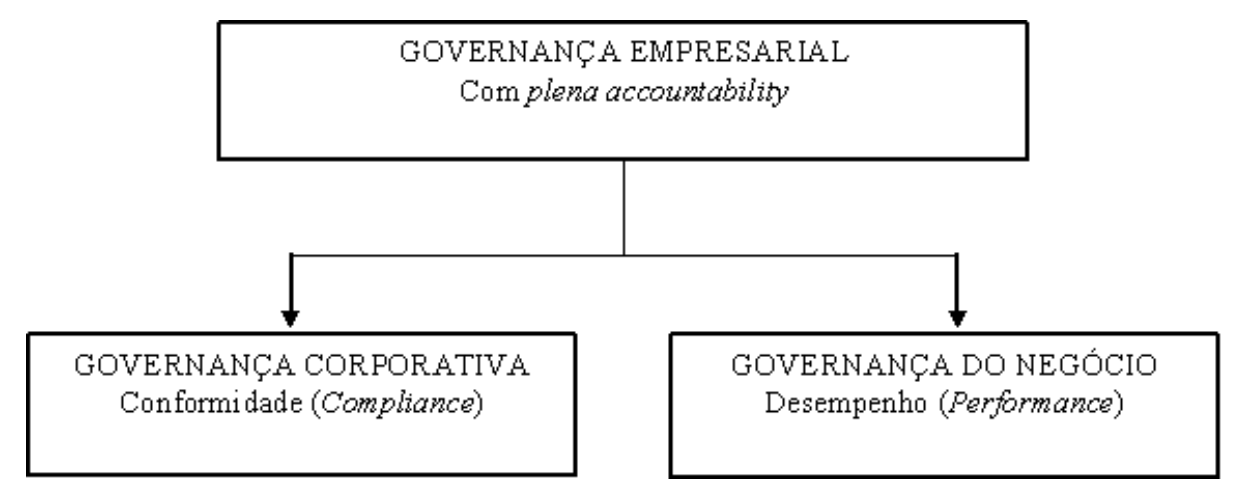

No módulo da Governança Corporativa, o que se busca é evidenciar a accountability da empresa, em termos de conformidade (compliance) de suas operações às leis que regulamentam suas atividades no Brasil. Cabe ao contador evidenciar, por meio de uma adequada contabilização (bookeeping), a conformidade contábil da empresa às normas legais que regulam suas atividades no Brasil.

No módulo da Governança do Negócio, o que se busca evidenciar é a accountability da empresa, em termos de otimização do desempenho (performance) econômico-financeiro do seu negócio, aderente às expectativas e aos desejos de seus acionistas e stakeholders. 
Cabe aqui à Contabilidade (accounting) realizar a interpretação das informações contábeis, geradas pelos relatórios financeiros da empresa, em termos de fidedignidade e compreensibilidade da representação dos fenômenos que lhes deram origem e comunicar de forma transparente aos acionistas e aos stakeholders os riscos associados aos fluxos de caixa de futuros negócios.

\subsubsection{Curso de Graduação em Ciências Contábeis (Accountancy) no Brasil}

Este é o nome que se deu ao curso de graduação destinado a formar o contador no Brasil, cujo exercício profissional se dá mediante registro nos Conselhos Regionais de Contabildidade, sob a coordenação geral do Conselho Federal de Contabilidade (CFC).

De acordo com o pressuposto assumido neste trabalho, em sendo a accountability a razão de ser da contabilidade, o curso de graduação em Ciências Contábeis deveria ser programado e executado, visando possibilitar ao estudante do curso de graduação em Ciências Contábeis a implementação, com sucesso, dos conceitos inerentes à teoria do agenciamento, bem como a mensuração e a gestão estratégica dos custos de agenciamento.

Isso tem o significado de que os cursos de graduação em Ciências Contábeis têm a missão de formar profissionais capazes de executar, com eficiência e eficácia, em primeiro plano, as atividades de contabilização (bookeeping), visando à conformidade contábil das empresas às leis que regulam suas atividades.

Em complementação a essa atividade profissional essencial, diga-se de passagem, a qualquer pessoa física ou jurídica, pública ou privada, os cursos de graduação em Ciências Contábeis deveriam preparar os alunos, futuros contadores, ao exercício da atividade de Contabilidade (accounting) propriamente dita. Essa atividade consiste em materializar a prática da interpretação das informações contábeis contidas nas demonstrações financeiras, vis-a-vis, em confronto com os fenômenos que lhes deram origem. Não se trata da tradicional disciplina de Análise de Balanços, mas da semiótica aplicada à contabilidade.

Sob a perspectiva acima, a expectativa que se gera nos candidatos aos cursos de graduação em Ciências Contábeis é a de que ele será reconhecido pela sociedade como um profissional com o mesmo status social, político e econômico de igual nível aos dos colegas de outras profissionais tradicionais no mercado.

Além das preocupações acima, constata-se no Brasil a lamentável ausência de programas de doutoramento em Contabilidade. Em nossa opinião, essa é, na verdade, uma das questões mais sérias e, portanto, críticas que contribuem para que os alunos se limitem a aprender nos cursos de graduação em Ciências Contábeis os procedimentos técnicos e as leis que regulam a atividade de contabilização (bookeeping). Quando muito, os alunos recebem excelentes aulas de análise de balanços acompanhadas de exercícios de cálculos de índices. Mas a análise de balanços não têm nada a ver com a hermenêu- 


\section{repc}

tica aplicada à análise de balanços. Estas dependem, essencialmente, da presença de professores doutores em Contabilidade nas salas de aula, com profundos conhecimentos teóricos e práticos de interpretação e comunicação contábeis, ou seja, de contabilidade (accounting), por meio da análise de demonstrações financeiras, das notas explicativas e dos relatórios de administração.

\subsubsection{Integração Conceitual e Sistêmica entre a Contabilização (Bookeeping) e a Contabilidade (Accounting)}

De acordo com Taggart (1951: pg.141-151) e Mason et al (1959: pg.5), deve-se fazer uma clara distinção entre contabilização (bookeeping) e contabilidade (accounting). Podese dizer que a primeira está contida na segunda, mas a contabilidade (accounting) é uma matéria analítica e seu escopo é diferente da contabilização (bookeeping).

O contador, graduado em Ciências Contábeis, desenha o sistema de registros contábeis para o técnico em contabilidade usá-lo com o objetivo de efetuar com due diligence a contabilização (bookeeping) dos dados relativos às atividades e às transações realizadas pela empresa, registrando com fidedignidade os valores dos fenômenos a que correspondem, elaborando e, finalmente, divulgando aos acionistas e stakeholders as demonstrações financeiras acompanhadas de notas explicativas e relatório da administração.

As demonstrações financeiras são direcionadas pela necessidade de prestação de contas que a empresa e seus dirigentes deverão fazer aos acionistas e stakeholders reunidos em Assembléia Geral e/ou toda vez que forem solicitados. Trata-se, neste caso, de quitação da accountability relacionada com a evidenciação da conformidade (compliance) da empresa às leis e outros institutos jurídicos que regulam suas atividades no Brasil.

A outra forma de quitação da accontability da empresa e seus dirigentes está relacionada com a prestação de contas que se faz ao Conselho de Administração, em decorrência das responsabilidades assumidas e/ou atribuídas aos dirigentes da empresa, evidenciando a eficácia do desempenho (performance) econômico-financeiro dos negócios da empresa.

As duas formas de prestação de contas estão presentes no modelo de governança empresarial da Ifac sob o nome de plena accountability.

\subsection{Accountability}

\subsubsection{Conceito Básico}

Segundo Campos (1990, p.30-49), ainda não foi possível encontrar em nossa língua pátria um vocábulo que corresponda fielmente ao significado do termo accountability. Hoje, entretanto, como resultado das pesquisas que já foram realizadas, podemos dizer que a palavra confiabilidade representa adequadamente o seu correspondente em inglês accountability. Preferimos, contudo, por razões socioculturais e psicológicas, manter, por ora, a expressão já consagrada em nossa literatura acadêmica de accountability. 
Para ljiri (1975, p.32), os registros feitos por meio da contabilização (bookeeping), ou seja, escrituração por partidas dobradas são mantidos para cada transação porque o agente-responsável (accountable) perante o principal da organização deve fazer a prestação de contas de forma, sob a ótica dos conceitos do true and fair value, para quitar suas responsabilidades perante o órgão ou a instituição a que está vinculado. A esse conceito se dá o nome de accountability. Visto desta maneira, durante séculos, a accountability tem sido, claramente, a espinha dorsal da contabilidade.

Ao enfatizar a importância do conceito de accountability, ljiri (1975, p.33-35) diz que a atual prática vigente em contabilidade poderá ser mais bem interpretada se nós olharmos para a accountability como sendo seu principal objetivo. Ele sugere que se nós não voltarmos o nosso olhar para a contabilidade (accounting) dessa maneira, as práticas contábeis correntes de contabilização (bookeeping) pareceriam ser inconsistentes e irracionais em relação aos fenômenos por ela observados, reconhecidos, mensurados e avaliados.

Para Covaleski e Michael (1986, p.297-319), a sobrevivência social, política e econômica das instituições em um mundo construído socialmente e, nesse contexto, as modernas sociedades anônimas de capital aberto em particular, dependem da eficiência e da eficácia de uma complexa rede interna e externa de accountability.

Como já se disse, a accountability de uma organização tem início com a contabilização (bookeeping), ou seja, escrituração por partidas dobradas das atividades e das transações realizadas por ela e termina com as informações e as comunicações geradas pela Contabilidade (accounting) sobre o desempenho econômico-financeiro do negócio e suas conseqüências futuras, em termos de fluxos de caixa. Podemos dizer que a accontability é o que distingue a contabilidade de outros sistemas de informação.

Ao abordar o tema accountability no livro texto Critique of Accounting, Mattessich (1995, p.213) afirma que há muito tempo os contadores vêm sendo submetidos à vaga noção de que o lado do ativo do balanço mostra coisas concretas, portanto, relacionadas com a realidade, ao passo que o lado do passivo mostra coisas abstratas, ou seja, puramente conceituais. Essa confusão, que decorre da dicotomia entre o que é físico e o que é social, tem levado alguns pesquisadores acadêmicos à afirmação de que o capital e a renda são noções puramente abstratas, que não têm nenhuma correspondência com a realidade. Nesse contexto, no que diz respeito à accountability, torna-se necessário que se comparem coisas reais com as contas que representam de forma abstrata aqueles eventos.

As figuras são formas de representação de coisas e eventos e não é por mera coincidência que, por volta de 8000 anos a.C., os contadores da Suméria já faziam uso dessa forma de representação concreta antes de convertê-la em uma representação abstrata.

Leemans (1950, p.22-23) nos relata o caso de accountability que ocorreu 
aproximadamente no ano 3250 a.C. na Suméria entre o comerciante Tamkarum e o seu agente que, para cumprir suas metas de vendas tinha diante de si longas jornadas de viagens de negócios.

O Tamkarum fornecia mercadorias e dinheiro (prata) ao seu agente que, ao retornar da viagem de negócios deveria fazer a prestação de contas de forma justa e legítima, sob pena de ser punido acordo com o que estabelecia o Código de Hamurabi. Esse registro histórico de natureza arqueológica demonstra que o conceito de accountability é algo inerente ao ser humano e suas características de humanidade a que se referia Aristóteles, uma vez que sua quitação ocorria como decorrência da necessidade de se contar com os conhecimentos próprios da contabilidade que, por sua vez, embora de origem muito mais antiga, teve seus primeiros registros arqueológicos na cidade de Uruk na região da Suméria, localizada entre os rios Tigres e Eufrates, ou seja, na Mesopotâmia.

Os "99§§ss do código de Hamurabi continham regras específicas para o suprimento de dinheiro (prata) para uma finalidade especial, notoriamente um harranum":

sum-ma tamkarum

a-na sammalim

kaspam a-na

... ri

id [-di-] in ma

a-na harranim it-ru-us-sú

[kasap ip-qi-(?)] du-sum se um tamkarum

deu a um samallum

prata (para aplicar em negócios?)

e ele enviou-lhe uma rota (journey)

então, o samallum [shall?] em sua caravana (journey)

a prata, que Ihe tinha sido confiada (?)

Esse $\S$ pressupõe que o Tamkarum havia fornecido dinheiro a um samallum para uma jornada de negócios (journey). Provavelmente, o Tamkarum foi até mesmo o primeiro banqueiro do mundo. A palavra usada como journey (harranum) é literalmente uma rota de viagens de negócios. O propósito para o qual o samallum foi enviado para essa viagem de negócios (journey) foi mencionado no hiato. É difícil preencher os gaps, mas parece ser verdadeiro que o propósito da viagem era o de realizar negócios. A dificuldade aumenta mais ainda pelo fato de que a palavra samallum ou a sua derivada é encontrada muito raramente em textos babilônicos e porque sua etimologia não é muita conhecida.

Em seu conjunto, os $99 \S \S s s$ parecem sugerir que ele era um agente-viajante ou comerciante de varejo, mas eles também denotam a possibilidade de que o agente permanecia por um algum tempo distante dos olhos do Tamkarum. Quando comparado ao Tamkarum ele é chamado de o pequeno comerciante. Um interessante exemplo de como àquela época ocorria a prestação de contas, visando à accountability do agente em relação ao seu principal, pode ser observado por meio do seguinte exemplo: 


\section{repec}

[sum-ma a-sar] il-li-ku
[ne-me-lam] i-ta-mar
si-ba-at kaspim
ma-la il-qú-ú
i-sa-ad-dar-ma
u4-mi-su
i-ma-na-nu-ú-ma tamkar-su
i-ip-pa-al

[sum-ma a-sar] il-li-ku

[ne-me-lam] i-ta-mar

\author{
Se, para onde ele foi, \\ conseguiu obter (has seen) lucro \\ então, os juros da prata (dinheiro) \\ correspondendo ao que ele \\ recebera \\ será dada entrada em sua conta, \\ alguém contará seus dias \\ e ele satisfará (prestação de contas) \\ o seu tamkarum.
}

Ainda a propósito de accountability, recentemente Davis, Lukomnik e Pitt-Watson (2006, p.13-243) lançaram na FEA/USP o livro intitulado The New Capitalists, como parte do Simpósio Internacional de Governança Corporativa, realizado no dia 19.10.2006, como parte das comemorações dos 60 anos de sua criação. Esses autores introduziram alguns conceitos novos tais como o da economia civil, novos capitalistas, círculo da accountability, ecossistema do novo capitalismo e agenda do novo capitalista.

No que diz respeito ao círculo da accountability, esse tema foi estudado pelos autores do livro no contexto das gigantescas corporações da economia civil onde surge a figura do chamado novo capitalista. O que vem a ser a economia civil? É um conceito que busca retratar o que já está acontecendo nos atuais mercados de capitais, onde os proprietários de ações negociadas em bolsas de valores, mundialmente acessíveis, graças à globalização da economia, estão se tornando absolutamente anônimos, chamados de novos capitalistas.

Os chamados novos capitalistas representam dezenas de milhões de acionistas, espaIhados pelo mundo inteiro, que aplicam disponibilidades obtidas por meio de fundos de pensões, aposentadorias, fundos de investimentos, fundos mútuos, planos de capitalização, etc.

Já o círculo da accountability é a representação de uma visão sistêmica do modelo de gestão estratégica das implicações da accountability sobre o desempenho da agenda de negócios dos novos capitalistas, no contexto da nova economia civil e que, segundo interpretação de nossa inteira responsabilidade, requer o estudo de uma nova especialidade contábil, ou seja, a contabilidade civil.

\subsubsection{Accountability no Setor Público}

De acordo com Cameron (2004:59-67), accountability é também um importante elemento que caracteriza a boa governança no setor governamental. O conceito envolve a obrigação de se responder pelos resultados de decisões ou ações, freqüentemente, para prevenir o mau uso do poder e outras formas inadequadas de comportamento. A noção de accountability no setor público pode ser dividida da seguinte maneira: 
- dando explicações a todos os cidadãos, sejam eles eleitores ou não;

- provendo informações posteriores sobre fatos relevantes, quando se tornarem necessárias;

- revendo e, se necessário, revisando sistemas ou práticas para atingir as expectativas dos cidadãos sejam eles eleitores ou não; e

- concedendo compensações ou impondo sanções.

De acordo com Schedler (1999), apesar de instituições financeiras, líderes de partidos, entidades de classe, jornalistas e cientistas políticos terem descoberto a enorme importância da accountability no setor público, o termo ainda está por ser explorado de maneira mais adequada e com a profundidade que, efetivamente, o tema merece. Por essa razão, estudiosos da administração pública também se mostram fortemente interessados em difundir esse conceito com maior vigor, mormente em ambientes que primam pelo respeito aos princípios democráticos.

$\mathrm{Na}$ verdade, busca-se disseminar a idéia essencial da accountability que, segundo Levy (1999), é a obrigação que alguém tem de prestar contas ao assumir responsabilidades perante outrem. No âmbito das organizações públicas, essa obrigação pode ser entendida como um dever imposto àqueles que detêm o poder de Estado, no sentido de darem visibilidade aos seus atos e, conseqüentemente, gerar um maior grau de confiança entre governantes e governados.

Considera-se, inclusive, que a accountability não se limita à premissa da prestação de contas, mas se encarrega também de definir os objetos e fenômenos sobre os quais se devem prestar contas. Procurando reforçar o verdadeiro sentido do termo accountability, Stark \& Bruszt (1998) acrescentam que a expressão "prestar contas de" nos remete simultaneamente a dois termos fundamentais: contabilidade e narrativa.

Parece haver consenso na literatura de que o fundamento dos sistemas democráticos está, verdadeiramente, na accountability, já que a informação é um pressuposto básico da transparência dos negócios públicos em uma verdadeira e legítima democracia. Sem informações adequadas a respeito da gestão pública, os cidadãos ficam privados de realizar julgamentos adequados a respeito dos atos praticados por seus governantes.

A propósito, O'Donel (1998) salienta que um dos aspectos mais importantes da accountability é exatamente a obrigação que o governante tem de prestar contas dos seus atos com suficiente transparência para que os cidadãos possam avaliar a sua gestão e, em razão disso, ratificá-la ou refutá-la.

No contexto da Lei de Responsabilidade Fiscal, essa obrigação ganha dimensões ainda mais relevantes, haja vista o conjunto de sanções que dela resultam para os governantes que sonegarem informações sobre suas práticas. Esse tema tem sido tratado com tanto interesse ultimamente que já se considera como imprescindível o fortalecimento de instituições 
independentes do governo para oferecer à coletividade as informações de que ela precisa para o efetivo exercício da cidadania.

De acordo com Schedler (1999), a essência da accountability na esfera pública pode ser considerada sob duas dimensões igualmente importantes e de cunho complementar. A primeira delas, como já se mencionou neste trabalho, é a capacidade de resposta dos governos, ou seja, a obrigação que os mandatários têm de dar satisfações à sociedade a respeito de seus atos. A segunda dimensão se relaciona com o poder de impor sanções aos que se desviam do cumprimento de suas obrigações.

Em razão disso, esse autor entende que a accountability, em seu sentido estritamente político, vai além da simples geração de dados. Mais do que isso, em sua avaliação, é necessário que haja instrumentos que viabilizem a punição do comportamento inadequado. Em função disso, cabe à própria sociedade verificar até que ponto Ihes são oferecidos os instrumentos essenciais à verdadeira accountability. De fato, não é razoável falar em accountability e muito menos pressupor a sua eficácia, num contexto em que o acesso à informação for limitado ou ainda se essa informação não for fidedigna, isto é, se ela não for fiel à essência dos fenômenos que busca representar.

Acesso à informação é uma característica essencial da accountability - virtualmente todas as formas de accountability residem na disponibilidade de informações oportunas e relevantes. Contudo, a informação será de pouco valor se não for utilizável para a retificação de quaisquer questões levantadas pelos interessados ou para se melhorar o desempenho. Ela pode também preencher uma importante função de suporte a decisões.

A questão sobre accountability é fundamentalmente a necessidade de se saber quem é contável/responsável (accountable) em relação a que/quem e para quê. No setor público de um país onde a cultura que prevalece é a do code law o processo de accountability pública é determinado em grande parte pela legislação e pelo sistema legislativo.

O poder legislativo provê a autoridade de aquisição da obtenção e uso de recursos para o setor público. Em muitos casos isto é realizado por intermédio da cobrança de taxas e apropriação dessas taxas ao Poder Executivo por meio do processo orçamentário.

Assim, o Poder Executivo se torna contável, ou seja, confiável (accountable) perante o Poder Legislativo pela gestão e uso de recursos providos a ele pelo Legislativo. O Poder Legislativo, por intermédio de seus membros representantes, torna-se contável, ou seja, confiável (accountable) perante o povo, que julga o desempenho do Governo e pode exercer sua influência pelo direito de voto por ocasião das eleições públicas.

Os servidores públicos prestam seus serviços ao Governo e são contáveis/responsáveis (accountable) perante seus superiores imediatos na escala hierárquica do Governo. Em um sentido mais amplo, eles são contáveis/confiáveis (accountable) por suas ações perante o Poder Legislativo e o povo. 


\subsubsection{Accountability no Contexto do Ofício Circular/CVM/SNC/SEP No 01/2005}

A simples leitura do ofício circular da CVM já nos induz à clara compreensão de que o conceito de accountability é a principal motivação de nossas autoridades monetárias, na regulação do mercado brasileiro de capitais. Vejamos atentamente a transcrição, a seguir, de alguns trechos que destacamos desse importante documento, onde se enfatizam as primeiras barreiras impostas pela cultura brasileira que está, essencialmente, atrelada à cultura do code law.

"[...] O objetivo da regulação contábil para o mercado de capitais está vinculado ao funcionamento das empresas na forma corporativa, ou seja, no conjunto de relações com os interessados no funcionamento da empresa (stakeholders) capaz de produzir efeitos econômicos e sociais. Esse objetivo relaciona-se, também, ao papel dos administradores, que têm responsabilidade primária sobre as contas da companhia, e com o papel dos auditores que expressam a sua opinião sobre as Demonstrações Contábeis e assumem coresponsabilidade pública sobre essa informação.

A regulação se constitui no arcabouço formal sobre o qual se dá a produção das informações contábeis e estabelece as condições mínimas para que se conheça a situação econômico-financeira da empresa. Isso, entretanto, não esgota as possibilidades de atendimento às necessidades informacionais dos agentes de mercado externos à companhia aberta e nem supre a velocidade com que essas informações devem chegar aos interessados. É necessário que a companhia faça o esforço permanente de aperfeiçoamento dessas informações e procure garantir a adequação e razoabilidade de seus procedimentos nesse esforço, particularmente se for considerado o problema da globalização das informações contábeis associado ao livre fluxo de capitais.

As diferentes soluções possíveis para o problema do registro e divulgação das informações contábeis no âmbito global podem ser resumidas nas alternativas de (i) reciprocidade ou reconhecimento mútuo das normas e práticas estrangeiras, o que trazem problemas de compreensão e entendimento do ambiente contábil de outros países; (ii) da reconciliação, que predomina hoje conforme pode ser observado nas notas explicativas de reconciliação de resultados e patrimônio; e, finalmente, (iii) do uso de padrões internacionais, que é buscado de forma consensual pelos países e mercados.

O sentido principal da evolução regulatória no Brasil está na convergência com os pronunciamentos internacionais e, para isso, o Ibracon e a CVM vêm se empenhando na adaptação das regras emitidas pelo IASB, os International Financial Reporting Standards (IFRS), para o ambiente contábil brasileiro. Essas ações, entretanto, implicam ultrapassar algumas barreiras para a integração dos mercados de capitais e a conseqüente necessidade de harmonização contábil.

A primeira barreira está no ambiente jurídico brasileiro em que a Lei é a principal fonte do direito (direito romano, ou code law) comparado aos países de direito jurispru- 


\section{repc}

dencial (direito consuetudinário ou common law), baseado, portanto, em decisões judiciais (precedentes com força obrigatória). Nesses últimos, a estrutura conceitual com princípios contábeis geralmente aceitos buscou a referência do investidor como usuário principal e a substância econômica sobre a forma jurídica como referência conceitual. Em oposição, nos países com base no Direito Romano - onde os usuários principais foram os credores e o fisco -, a referência principal baseou-se na conformidade à Lei ou na orientação pela norma (rules oriented). Temos, portanto, no ambiente contábil brasileiro a mudança feita pela lei sob a égide do direito romano, o que é de tramitação demorada e não consegue acompanhar a evolução dos negócios.

Dentro do princípio de auto-regulação, que permite à CVM compatilhar com instituições privadas papéis e atividades com o objetivo de aumentar a eficiência da atividade regulatória, o Projeto de Lei $n^{\circ} 3.741$ cria a possibilidade do exercício das funções de pesquisa e emissão de pronunciamentos contábeis a uma entidade multirepresentativa. Essa entidade deve contemplar os representantes dos diversos segmentos afetados pela informação contábil das companhias abertas e ser capaz de produzir normas contábeis para aplicação no mercado de capitais brasileiro, tendo como referência as normas internacionais, o que traria maior flexibilidade ao processo de normatização contábil.

A segunda barreira trata das questões econômico-fiscais e a necessidade de separação de fato das escritas para conciliar os interesses do Fisco e da informação prestada aos investidores. O Projeto de Lei $n^{\circ} 3.741$, sem prejuízo da segregação contida na lei atual, apresenta uma outra forma de separação para a conciliação desses interesses.

A barreira cultural é importante como fator fundamental na compreensão de regras internacionais que só podem ser entendidas a partir de uma base de educação e treinamento sofisticados. Nesse sentido, os pronunciamentos escritos em inglês e a complexidade das normas estabelecem um nível de exigência alto que, neste momento, somente alguns centros são capazes de atender à formação do profissional apto a compreender e a aplicar essas normas. Essa barreira concorre para o desinteresse pelo assunto, em que pese a inevitável necessidade de enfrentamento da convergência com as normas internacionais no futuro imediato.

A aplicabilidade das normas internacionais no mercado de capitais brasileiro também deve ser escalonada, haja vista a existência de empresas com acesso somente ao mercado de capitais brasileiro e outras companhias que já obtiveram acesso ao mercado global de capitais. As exigências sobre as informações devem ser diferentes, tendo em vista as condições de porte e natureza dessas companhias.

Na situação atual, existem diversos pontos de divergência entre as normas brasileiras e internacionais, dos quais, no entender da área técnica da CVM, podem ser destacados: (i) a introdução e aplicação do método do valor justo (fair value), particularmente nas empresas não-financeiras; (ii) o tratamento contábil dos instrumentos financeiros, 
também relacionado ao método do valor justo; (iii) a contabilização e a evidenciação nas Demonstrações Contábeis das operações de arrendamento mercantil; (iv) o tratamento contábil das reestruturações societárias (fusões, incorporações e aquisições); (v) o tratamento contábil das subvenções governamentais; e (vi) a divulgação por segmento de negócios [...]".

\section{CONSIDERAÇÕES FINAIS E RECOMENDAÇÕES}

As motivações para a realização deste trabalho foram muitas, as quais nos perseguem há muito tempo, pelo menos há quinze anos. Entretanto, neste trabalho, concentramos nossos esforços em três questões: (1) a questão levantada pelo Professor Henry Rand Hatfield de dezembro de 1923, que se refere ao status dos que se dedicam ao ensino, à pesquisa e/ou às atividades profissionais em contabilidade; (2) a questão suscitada por Vernon Kam através de uma questão que consideramos ser de natureza transcendental para a evolução das Ciências Contábeis (accountancy) e que tem profundas implicações sobre a gestão dos processos de educação contábil no Brasil e sobre o próprio status social, político e econômico de nossa profissão; e, finalmente, (3) a questão do tema deste trabalho, ou seja, a compreensão se é, ou não, a accountability a razão de ser da Contabilidade.

Na primeira questão, ou seja, aquela levantada por Hatfield, o que tem acontecido no Brasil é que, desde sua criação em 1945, nos cursos de graduação em Ciências Contábeis (accountancy) as disciplinas específicas de contabilidade (accounting), com raríssimas exceções, sempre foram e continuam sendo ministradas, em grande parte, por renomados e experientes profissionais em contabilização (bookeeping), mas não em Contabilidade (accounting). Precisamos, na verdade, nos esforçar para que a sociedade disponha de um número cada vez maior de doutores em Ciências Contábeis, por meio de programas de pós-graduação que mereçam a classificação nível "4" da Coordenação de Aperfeiçoamento de Pessoal de Nível Superior (Capes).

Na segunda questão, ou seja, aquela suscitada por Kam, constata-se que, com exceção de ludicibus e seus seguidores na FEA/USP, o tema "o que a contabilidade é na sua essência" não tem merecido ainda a devida atenção em nosso País. Nosso entendimento é que deveríamos estimular e suportar financeiramente doutorandos nessa área de pesquisa, especialmente agora que tantos os bancos como as sociedades anônimas de capital aberto já são obrigadas a elaborar e divulgar suas demonstrações financeiras consolidadas de conformidade com os padrões internacionais de contabilidade IFRS.

Já na terceira questão, ou seja, naquela em que Yuji ljiri (1975) afirma que a accoun-

tability é a razäo de ser da contabilidade, as pesquisas realizadas neste trabalho revelaram que esse conceito já era do conhecimento humano por volta dos anos 3250 a.C. Nos pró- 
prios textos bíblicos, encontramos em Mateus, 25, v.14 em diante, parábola dos dez talentos, que o conceito de prestação de contas com vistas à quitação da accountability também já era praticada por volta do século 32 d.C.

Ademais, as instruções e as orientações normativas emanadas do Banco Central e da Comissão de Valores Mobiliários (CVM), no sentido de que os bancos brasileiros e as sociedades anônimas de capital aberto, respectivamente, deverão obrigatoriamente, a partir de 2010, elaborar e divulgar suas demonstrações financeiras consolidadas de conformidade com as normas contábeis internacionais do International Financial Reporting Standards (IFRS), foram inspiradas sob a égide da accountability.

Finalmente, devemos considerar que cabe ao contador a responsabilidade ética, moral e profissional de elaboração e divulgação, com transparência, das demonstrações financeiras, das notas explicativas e dos relatórios da administração com a mais perfeita transparência, sob a ótica da doutrina do true and fair view. Em caso de negligência, má-fé, dolo ou imperícia caberá no Brasil a aplicação das penalidades previstas em lei e nos EUA na Lei Sarbanes-Oexley.

Portanto, a contabilidade (accounting), com base numa adequada contabilização (bookeeping) com due diligence, é a forma pela qual as sociedades anônimas de capital aberto devem fazer a prestação de contas a seus acionistas, investidores, stakeholders e à própria sociedade como um todo.

Aliás, a prestação de contas já é ela, em si mesma, uma expressão técnica que contém a palavra cont, a qual, por sua vez, é uma derivada regressiva do verbo contare denota, sob o olhar da semiótica contábil, a preocupação de representar os fenômenos de natureza econômico-financeira com transparência sob o domínio da doutrina true and fair view.

No modelo de prestação de contas que foi estudado, identificamos o conceito de accountability em dois formatos: exógeno e endógeno. No modelo da Ifac, encontramos o conceito de plena accountability, que está relacionada, de um lado, com a conformidade (compliance) da empresa às leis que regulam suas atividades no país e, de outro lado, com o desempenho (performance) aderente às expectativas e aos desejos de seus acionistas, aos stakeholders e à própria sociedade como um todo.

Aos que o desejarem, há ainda um longo caminho a ser trilhado em matéria de estudos sobre a accountability como a razão de ser da contabilidade. Por ser uma matéria ainda em desenvolvimento no Brasil, muitos aspectos teóricos, epistemológicos e pragmáticos ainda deverão ser estudados e modelados em termos de aplicação, por meio de estudos de casos brasileiros. Em matéria de pesquisa de campo, provavelmente, o Banco Mundial já havia manifestado o desejo de que a Fipecapi realizasse a pesquisa no início dos anos 90 . Mas temos a certeza de que surgirão muitas oportunidades no próprio contexto dos atuais problemas sociais, políticos e econômicos brasileiros. 


\section{REFERÊNCIAS}

ALMEIDA, João Ferreira de, Bíblia Sagrada, in Matheus, 25 v. 14, RJ: 1958.

ARANHA, Carmen S., Exercícios do Olhar, in AJZENBERG, Elza, Arteconhecimento, SP: MAC/USP, 2004, p.83-95.

CAMERON, Wayne, Public Accountability: Effectiveness, Equity, Ethics, Austrália: in Australian Journal of Public Administration, December 2004, p. 59-67, with copyright of National Council of Public Administration, published by Blackwell Publishing Limited.

CAMPOS, Anna Maria, Accountability: quando poderemos traduzi-la para o português, RJ: Revista de Administração Pública, fev/abr. 1990, página 30-49.

CARVALHO, Mário A. Santiago de, O Ente e a Essência de Tomás de Aquino,Versão do Latim e Introdução,, Porto: Edições Contraponto, 1995.

COVALESKI Mark and AIKEN, Michael, Accounting, and Theories of Organizations: Some Preliminary Considerations, UK: in Accounting, Organizations and Society, Vol. $11 \mathrm{~N}^{\circ} 4 / 5$, 1986, pp 297-319.

DAVIS, Stephen, LUKOMNIK, Jon e PITT-WATSON, David, The New Capitalistas-How Citizen Investors areReshaping the Corporate Agenda, Boston, Harvard Business School Presst, 2006, p. 13-243.

HENDRIKSEN, Eldon S. and Van Breda, Michael F., Accounting Theory, NY: Irwin, 1992 pp.111.

IJIRI, Yuki, Theory of Accounting Meassurement, Studies in Accounting Research 10, NY: American Accounting Association, 1975.

IUDICIBUS, Sérgio de, Teoria da Contabilidade, SP: Editora Atlas, 1995, p.28-29.

JENSEN, Michael C., and Mcckling, William, Theory of the Firm. Managerial Behavior, Agency Cossts and Ownership Structure, Boston: Journal of Financial Economics, Vol.3, N4, October 1976, pp 305-360. 
LEEMANS, W.F., The Old-Babylonian Merrchant-His Business and His Social Position, Holland: E.J.Brill, 1950 pp 22-23.

LEVY, Evelny. Controle social e controle de resultados: um balanço dos argumentos e da experiência recente. O público não estatal na reforma do estado. Rio de Janeiro, FGV, 1999.

MASON, Perry, DAVIDSON, Sidney, SCHINDLER, James S., Fundamentals of Accounting, NY: Holt, Rinehart and Winston, 1959.

MATTESSICH, Richard, Critique of Accounting, LONDON: Quorum Books, 1995, pp. 2.

MATTESSICH, Richard, Critique of Accounting, LONDON: Quorum Books, 1995, pp. 3.

NAKAGAWA, Masayuki e PINHEIRO, Paulo Bekmessian, Origem Genética da Contabilidade. In Congresso USP de Contabilidade; SP, FEA/USP, 2004.

O’ DONEL, Guillermo. Accountability e novas poliarquias. Lua Nova. São Paulo, n 44, 1998.

SCHEDLER, Andréas. Conceptualizing accountability. In S. SCHEDLER, A. et all. The selfrestraing state. Power and accountability in new democracies. Boulder and London: Lynne Rienner Publishers, 1999.

SCHMANDT-Besserat, Denise, Before Writing - From Counting to Cuneiform, TX: Austin, 1992.

SCHMIDT, Paulo, História do Pensamento Contábil, RS: Editora Bookman, 2000.

SOARES, Guido, Common Law, SP: Editora Revista dos Tribunais, 1999.

STARK, David, BRUSZT, Laszblo. Enabling Constraints: fontes constitucionais de coenrência nas políticas públicas no pós-socialismo. Revista brasileira de ciências sociais. São Paulo, V. 13, n³6, 1998.

TAGGART, Herbert, F., Cost Accounting versus Cost Bookeeping, NY: The Accounting Review, Vol. XXVI N², April 1951, p. 141-151. 